\title{
FACTORES SOCIOCULTURALES QUE INCIDEN EN EL COMPORTAMIENTO TERRORISTA*
}

Inés Tardel Marqués

El presente trabajo tiene por objeto destacar los aspectos socioculturales que afectan a la acción terrorista, considerada como uno de los grandes flagelos que aquejan al cuerpo social. Conjuntamente, se intenta individualizar un punto de partida de respuestas posibles que pudieran ser útiles para análisis posteriores. El enfoque es sociológico, es decir, considera la influencia de los grupos, de las instituciones sociales y de la sociedad global total en el comportamiento terrorista, considerado como la forma más extrema de conducta desviada.

Se parte del supuesto de que sociedad, cultura y personalidad están estrechamente ligadas conformando una realidad social y, que sólo con fines analíticos es posible delimitar fronteras precisas entre ellas. El aspecto bioquímico y fisiológico, aunque representa la razón necesaria del ser social, no se considera por estar suficientemente estudiado en su relación con la personalidad.

Lo social, lo cultural y lo psíquico ofrecen en común el hecho de estar implicados en toda acción humana. La acción social está formada por un conjunto organizado de interacciones y de roles unidos entre sí por una red de expectativas mutuas. Estas expectativas poseen un significado para cada uno de los individuos interactuantes gracias a los modelos y valores de la cultura y a las expresiones simbólicas, que las rodean y representan. Por la otra parte, cada persona aborda la acción social a través de un sector más o menos importante de su personalidad: actúa y reaccio-

* Ponencia presentada al Primer Congreso Iberoamericano de Facultades de Derecho y Especialistas sobre el tema:

"Terrorismo y Estado de Derecho". Viña del Mar, enero 1987. 
na de acuerdo con lo que ella es, con todo aquello que le confiere su carácter único y singular.

Los sistemas social y cultural existen en una relación dialéctica, en que el primero funciona como un sistema normativo de interacciones y de roles al proporcionarle la cultura los valores compartidos. A su vez, el sistema cultural sólo existe si se crea y recrea en la continua red de interacción y de relaciones sociales, siendo por ello, tanto una condición como una consecuencia. $Y$, la personalidad aporta a los dos sistemas precedentes, la energía vital para su funcionamiento: las motivaciones que inducen a los individuos a actuar en las situaciones en uno $u$ otro sentido.

El proceso interactivo se cristaliza en forma de relación social, las cuales, a través del tiempo se van institucionalizando, confiriendo una fisonomía propia a la organización social, la cual, a su vez, actualiza los valores centrales en la normativa que rige la convivencia de los miembros de la sociedad. Así, por ejemplo, se habla de que la sociedad tradicional se caracterizaría por un estilo particularista en la distribución de las labores económicas importantes, predominando el principio de adscripción en la regularización de las relaciones estructurales sociales, en especial en su dimensión económica; con un estilo difuso en la ejecución de las tareas (como el típico "maestro chasquilla" nuestro); $y$, en que la orientación de las personas que ocupan las posiciones políticas y económicas influyentes, está determinada en gran parte, por sus intereses personales. La sociedad desarrollada, en cambio, se caracterizaría por el predominio del universalismo como la forma más racional y eficiente de la distribución de recursos; siendo la libre consecusión la pauta que caracteriza la distribución de los bienes económicos (la libre empresa); con una exigencia de descripción precisa de los roles laborales y la especificación en la asignación de funciones; $y$, los detentores de cargos en la elite gobernante, mantendrían relaciones colectivamente orientadas hacia objetivos sociales importantes. Todos estos factores se encontrarían en mayor o menor grado y encierran una importancia relativa variable con respecto al desarrollo económico.

Todo cuerpo social para subsistir y mantenerse como tal debe satisfacer ciertas necesidades vitales. El orden social es una de ellas. Otra, y de igual importancia que la anterior, es que los individuos miembros se adapten al orden establecido. $Y$, una tercera, la necesidad de cohesión o solidaridad para mantener integrados a los individuos desarrollando en cada uno de ellos un cierto grado de fusión de una parte de sus "yo" individuales en un "nosotros".

La Historia nos demuestra que, aunque en términos generales, la mayoría de los individuos responde al sistema normativo ajustando su comportamiento, la mayor parte de su tiempo, a las normas formales e informales vigentes, desempeñando gran parte de las tareas societales atribuidas a sus miembros $y$, que aun cuando los grupos estén funcionando de manera más o menos orgánica, ninguna 
sociedad consigue de hecho que la totalidad de sus miembros se comporte todo el tiempo de la manera esperada.

El proceso adaptativo no es fácil de lograr, sobre todo en nuestras sociedades en proceso de modernización. El cambio sociocultural que implica este proceso, conlleva, inherente a él, una probabilidad mayor de desviación social que la que se da en aquellas cuyas estructuras permanecen relativamente estables.

El proceso de modernización en que nuestra región se haya involucrada, ha determinado cambios continuos en las distintas instituciones sociales, lo cual significa fuentes de tensión, las cuales, a su vez, generan problemas sociales, conflictos entre los diversos grupos, resistencia al cambio, movimientos de protestas y terrorismo. Aunque estos grupos son minoritarios son una realidad que debemos afrontar. Estas consecuencias nos muestran dos aspectos que están relacionados entre sí: el de la desorganización de las pautas de vida de algunos grupos y el de la creciente interconexión entre grupos diferentes que experimentan esos cambios $y$, sus choques mutuos y recíprocos. En ambos casos se da la probabilidad de que surjan comportamientos desviados.

La modernización es un proceso global de cambio social que sufre una sociedad tradicional que se va convirtiendo en moderna a través de la especialización de las esferas económica, política y social, las que empiezan a articularse de una manera racional y técnica. En este proceso se va produciendo un acercamiento entre elites dirigentes y masas dirigidas, acercamiento que deja al descubierto la apertura de las masas a nuevas formas de convivencia, produciendo en este sentido, una "movilización social" 1 lo que desintegraría al statu quo propio de las sociedades tradicionales, generalizándose el deseo de mejorar el nivel de vida individual y de la sociedad total. Así la modernización es entendida como un modo de integración de la sociedad total, como un modo de relación entre centro o elite y periferia o masa de la sociedad.

La modernización es un proceso activo y con carácter evolutivo. Necesita una forma de organización social cuyos marcos básicos legales y políticos garanticen "la libre distribución y acceso a las esferas y roles institucionales y la posibilidad de cambiar una situación personal mediante procesos de movilidad social" 2 . En otras palabras, la modernización necesita una diferenciación estructural creciente, movilización social, desarrollo político y económico que permita cambios cuantitativos y cualitativos.

El proceso de modernización aumenta la complejidad de la organización so-

1 Deutsch, Karl. Social Mobilization and Political Development, en American Political Sciencie Review N 55, Septbre. 1961, pp. 494 a 495.

2 Eisenstadt, Samuel, Modernización, Movimientos de Protesta y Cambio Social, Ed. Amourostu, Buenos Aires, 1972, pp. 251-259. 
cial, por los procesos migratorios internos, el creciente progreso científico y tecnológico, la racionalización en la división del trabajo y en la especificación de las funciones, etc. Todo ello genera puntos vulnerables en el sistema, los cuales se materializan en tensiones, alienaciones, problemas sociales y grupos conflictivos. Sólo en el caso que la sociedad funcionara como una máquina se podría hablar con precisión de orden. Pero sabemos que la sociedad es un conjunto de seres humanos que conviven compartiendo normas, ideas, valores. La sociedad es convivencia de hombres libres, cuya libertad si bien está condicionada, nunca resulta anulada. Estas dos fuerzas: libertad y determinismo se enfrentan confiriendo a la organización social una dinámica específica, la cual apunta a un continuo reajuste de funcionamiento para mantener la estabilidad que necesita el sistema social. Organización y desorganización son, entonces, dos aspectos de la misma realidad social.

En el proceso de cambio sociocultural necesariamente aparecerán puntos vulnerables en la organización social. Paradojalmente, uno de ellos lo genera el proceso político modernizante como consecuencia de la atracción de los grupos hacia el centro, aumentando sus expectativas de participación, las que al no cumplirse, generan sentimientos de alienación y anonimato frente a las esferas política y social.

El proceso de industrialización, con el avance técnico y científico, desarticula las pautas tradicionales de trabajo y producción, creando situaciones de subempleo y ciesempleo.

El proceso migratorio campo-ciudad y la urbanización ha desorganizado las comunidades rurales y generado los cordones marginales en la ciudad, con todos los problemas sociales que ello implica.

Los medios masivos de comunicación aportan modelos de convivencia y de consumismo difíciles de conciliar con una sociedad en vías de desarrollo. Conjuntamente aportan modelos de agresividad y de comportamiento desviado.

Los procesos de racionalización y secularización debilitan la confianza en los valores $y$ tradiciones aceptados y mantenidos por las generaciones mayores, incidiendo en la esfera familiar, provocando la llamada "brecha generacional" y las consecuentes tensiones.

La ética universalista, como opuesto de la personalización es otro de los factores de desajuste individual y colectivo, en las relaciones sociales del mundo entero.

Y, por último, el problema de la socialización es otro aspecto importante que considerar para la estabilidad de la organización social.

Por socialización se entiende el proceso por cuyo medio la persona humana aprende e interioriza, en el transcurso de su vida, los elementos socioculturales de su medio ambiente, los integra a la estructura de su personalidad bajo la influencia 
de experiencias y de agentes sociales significativos, adaptándose así al entorno social en cuyo seno debe vivir.

Tenemos, entonces, que las personas adquieren a través de la socialización, los conocimientos, los valores, los modelos, los símbolos, en suma, las "maneras de obrar, pensar y sentir" propias de los grupos y de las sociedades en que están insertos. Pero, como es imposible que una persona absorba todos los elementos de la sociedad y de la cultura, sólo algunos pasan a ser parte integrante de la estructura de su personalidad psíquica. La proporción y el tipo de elementos que la persona internaliza varía de un individuo a otro, pero una vez que están integrados en la personalidad, pasan a convertirse en obligación moral y en la manera de sentir, pensar y actuar sentida como natural. Así, de la propia conciencia de cada uno de los individuos brota la fuente de su conformidad y adaptación a su medio social, sea éste normal o desviado.

Pero, sucede que los valores, normas y actividades que hemos transmitido a la nueva generación no se corresponden con la naturaleza y contenido de las estructuras sociales con las que les toca vivir. La diferencia de estilos de vida entre una y otra generación se va acentuando en la medida que la sociedad se va modernizando, por el desplazamiento de los valores normativos institucionalizados reemplazándolos por otros acorde con los objetivos perseguidos. Esto deja a la nueva generación en una situación de ambigüedad que los haría propicios a integrarse a grupos desviados buscando la identidad perdida, ya que como vimos al comienzo de la exposición, las alteraciones en la estructura social afectan a los tres sistemas de la realidad social: el sistema de la personalidad, el de la cultura y el de la sociedad.

De lo expuesto hasta aquí, se desprende que los mismos elementos del proceso de socialización dan lugar a conductas que la sociedad considera como patológicas: crimen, delincuencia, terrorismo. También influye en este proceso cómo cumplen su papel los agentes de socialización, quienes a veces no son los más adecuados para esta misión, ya sean padres incapacitados, familias desunidas o, como cuando no se ejerce la función sobre todo los individuos como sucede con niños en situación irregular, ya sea por abandono o sin escuelas.

Además, al debilitarse la función coercitiva de los controles sociales por éste paso de un tipo de estructura tradicional a otro tipo de moderno o participativo, se produce un margen de mayor tolerancia para con la desviación social.

De acuerdo con la teoría sociológica, la desviación social no es una cualidad del acto que comete una persona, sino más bien una consecuencia de la aplicación de las reglas y sanciones que hacen los demás a quien o quienes hayan cometido una ofensa. Con frecuencia, la desviación de la norma en la conducta social coincide con la desviación psicológica.

En la desviación grupal, los individuos miembros rechazan la cultura de su 
sociedad pero, simultáneamente mantienen un alto grado de conformismo para con su grupo de pertenencia. Estos grupos refuerzan y sancionan la desviación; tienden a aliarse con otros grupos desviados (no es extraña la alianza terroristadelincuentes); protegen emocionalmente a sus miembros contra las críticas y condenas de los demás miembros de la sociedad; establecen una serie de normas de conductas estereotipadas; tienden a desarrollar un lenguaje privado y, mantienen ciertos valores en una posición denominante dentro de la interacción grupal. En suma, tienden a desarrollar una subcultura, terrorista en nuestro caso de análisis, con la cual se conforman en mayor o menor grado, de acuerdo a los procesos psíquicos de cada uno de los individuos. Estas características del grupo terrorista, sumadas a la de no contar con la sanción negativa informal de su grupo de pertenencia, facilitan el desarrollo de lealtades para con los miembros del grupo, reforzando su cohesión y su posición de rebeldía ante la sociedad.

Estudios realizados por sociólogos, como es el caso de Robert Merton ${ }^{3}$ han demostrado que la adaptación es la respuesta más frecuente, aun en situaciones favorables a comportamientos desviados. Pero siempre habría una minoría de inadaptados, quienes, estimo, se bifurcarían hacia los dos polos de un continuo de adaptación social. Los que se ubicasen hacia un extremo, tenderían a un comportamiento hiperconformista, serían defensores del statu quo, oponiéndose al cambio, incluso en forma violenta. A la inversa, los que se aproximen al polo contrario, tenderían en su punto más alejado, a un comportamiento de extrema desadaptación, atacando agresivamente el sistema vigente, preconizando los objetivos más radicales y los medios más violentos. Esto nos permitiría hablar de terroristas de derecha y de terroristas de izquierda.

Volviendo al autor recién citado, el punto vulnerable de la organización social está en el desajuste entre la estructura cultural, representada por un conjunto organizado de valores, los cuales prescribirían los objetivos para la sociedad y, la estructura social, representada a su vez en un conjunto de relaciones sociales, las cuales definirían los medios de acceso a las metas constitucionalizadas.

Ambas estructuras entrarían en una relación disyuntiva, denominada "anomia". La estructura social permite o facilita a algunas personas el competir por los objetivos perseguidos y que son deseados por todos los miembros de la sociedad (el éxito económico, por ejemplo). Estas personas seguirían las normas institucionalmente prescritas. Las otras personas, al dificultárseles o negárseles el acceso a competir por dichos objetivos, eligirían en algunos casos, algún modo anómalo de adaptación dentro de la estructura social influenciadas, en muchos casos, por agentes externos al sistema.

A través de un esquema de "medios-fines", representando los cauces institu- 
cionales y los objetivos sociales, respectivamente, Merton describe cuatro tipos de comportamientos desviado, siendo uno de ellos el "revolucionario" el que se acercaría al "terrorista" en cuanto ambos rechazan tanto los medios institucionales como los fines que persigue la sociedad. Los revolucionarios proponen nuevos medios y metas.

Los resultados de la investigación de Merton no dejan de ser alentadores en un sentido pues, aun cuando se viva una situación de anomia, las personas en su mayoría tienden a tener un comportamiento conformista. Pero, derivada de esta tendencia a la adaptación de los miembros de una sociedad, podría también pensarse que la mayoría de nosotros nos estaríamos adaptando a la presencia del terrorismo en nuestras sociedades.

Un aspecto que nos favorece a los países en desarrollo es el hecho de conocer el modelo de sociedad al cual aspiramos a llegar y que, por esto mismo, nos permite planificar con un grado mayor de probabilidad de éxito que si no lo conociéramos, las acciones encaminadas a lograr que el cambio cuantitativo y cualitativo pueda darse sin producir quiebres o dualidades estructurales que afecten al ajuste del ser humano y a la estabilidad de la organización social. 